\title{
ANÁLISE DO SISTEMA DE TRANSPORTE: VEÍCULO LEVE SOBRE TRILHOS
}

lara da Silva de França

Graduando em Engenharia Civil no Centro Universitário Augusto Motta - UNISUAM.

Rio de Janeiro, RJ, Brasil

iarafraan@gmail.com

Rayanne Sant'Ana da Silva

Graduando em Engenharia Civil no Centro Universitário Augusto Motta - UNISUAM.

Rio de Janeiro, RJ, Brasil

Rayannesantanadasilva.edi@gmail.com

José Roberto Moreira Ribeiro Gonçalves

Mestrado Acadêmico em Engenharia Agrícola e Ambiental pela Universidade Federal Rural do Rio de Janeiro, Brasil

Docente, UNISUAM, Rio de Janeiro, RJ, Brasil

joserobertoverde@gmail.com

\section{RESUMO}

O presente artigo aborda uma breve análise do transporte público no estado do Rio de Janeiro. Através de um estudo relativo ao projeto veículo leve sobre trilho (VLT), demonstrando a importância de incluir um bom planejamento do transporte, permitindo aos usuários maior integração com menor custo.

Palavras-chave: Transporte público, VLT, Planejamento. 


\title{
TRANSPORT SYSTEM ANALYSIS: LIGHT RAIL TRANSIT
}

\begin{abstract}
This article discusses a brief analysis of public transport in the state of Rio de Janeiro. Through a study related to the light rail vehicle (LRT) project, demonstrating the importance of including good transport planning, allowing users to integrate more with less cost.
\end{abstract}

Keywords: Public Transportation, LRT, Planning.

\section{INTRODUÇÃO}

1.1 O sistema de transporte: vlt (veículo leve sobre trilhos) e sua implementação

Atualmente, nos meios de transporte há a necessidade melhorias na estruturação do sistema coletivo, por serem fatores essenciais para o desenvolvimento socioeconômico da cidade do Rio de Janeiro. A população hoje é obrigada a conviver com transportes caros e pouco satisfatórios, que geram transtornos como, grande tempo de espera nas paradas de ônibus, veículos lotados, grande tempos de viagem, dentre outros, que se tornaram ainda mais evidentes. Visto isso se notou a carência de reformular o sistema, aprimorando a experiência e o conhecimento acumulado para analisar e implementar o projeto do VLT (Veículo leve sobre Trilhos), que inova e adota o sistema de alimentação dos veículos com tomada de energia no solo, desta forma, este é o projeto brasileiro que mais se aproxima dos mais recentes e modernos projetos implantados, visando um sistema integrado de transporte público, diminuindo assim os conflitos de tráfegos na cidade. Essas transformações são significativas em sua infraestrutura, que impactam no modo como a população se locomove diariamente, sendo usuários ou não deste sistema. 
O transporte público é o meio de transporte em que os passageiros utilizam o meio de locomoção de forma legal e pode ser utilizado por qualquer cidadão que se disponha a pagar o serviço terceirizado, a tarifa (WRIGHT, 1988). Apesar dos transportes públicos serem pagos, a população não recebe um sistema de qualidade, sendo identificadas necessidades urgentes no que se relaciona a eles.

A modernização dos sistemas de transportes públicos está diretamente associada à saturação das vias e superlotação, que são alguns dos resultados de sua desestruturação. Uma das alternativas para redução dessa saturação seria transportar mais pessoas ocupando menos espaço nas vias, e aprimorando os sistemas para média capacidade, a fim de realizem o papel fundamental na formação de uma rede que garanta mobilidade e acessibilidade em uma maior extensão da cidade. A influência do transporte atinge todas as pessoas e seu bem-estar econômico, ofertando valor ao ambiente em que vivem e, em casos de transporte ineficiente, frustrações, afetando o bem-estar (ARAÚJO, 2006).

O VLT (Veículo Leve sobre Trilhos) foi apresentado como parte da solução para os problemas apresentados no Sistema de Transporte Público, e é o maior representante do transporte público de média performance nos países em que já havia vias implementadas, como Alemanha, Holanda, França e algumas cidades dos EUA (VUCHIC, 2005). Além disso, desde o reconhecimento da sua importância, diversas linhas foram construídas em cidades de países desenvolvidos, como Inglaterra e Espanha e em desenvolvimento, como Turquia, Filipinas e México (VUCHIC, 2007).

Esta implementação tem como objetivo impactar uma redução de uma boa quantidade de veículos na via, com o aumento da capacidade do número de lugares e da velocidade operacional associado à redução da mão-de-obra empregada, a produtividade deste meio de transporte em termos de oferta de assentos-km por tripulação cresceu em torno de 20 vezes (VUCHIC, 2005) reduzindo drasticamente os custos operacionais.

A essência deste projeto é o fato de ser uma forma híbrida de transporte público, onde, um transporte ferroviário de passageiros em que o veículo, em relação ao tamanho e peso, está adaptado tanto para distribuir passageiros em áreas centrais com grande concentração de pedestres através de velocidades inferiores e prioridade de passagem reduzida, e graças ao design mais leve, a infraestrutura também pode ter um 
formato menor do que o exigido para o trem convencional (BRUJIN E VEENEMAN, 2009). Isso faz com que os passageiros cheguem mais rápido, dando a possibilidade de criar maior integração em volta da cidade por menor custo, tornando-a acessível. Esses fatores mostram que o VLT fornece uma ligação mais forte a cidade, contribuindo assim para uma maior integração (KIM, ULFARSON E HENNESSY, 2007).

Experiências como a da cidade de Sacramento, na Califórnia, mostram que a realização do sistema de VLT aumenta não somente a quantidade de passageiros transportados nas linhas de ônibus substituídas, como também o total de viagens realizadas via Transporte Público na cidade. O chamado fator trilho parece impactar simultaneamente a tendência dos usuários de utilizar o sistema e a imagem e o papel desempenhado por ele na integração da cidade (VUCHIC, 2007).

Segundo, o Ministério das Cidades (2006, p. 19) a mobilidade urbana corresponde:

“[...]" à facilidade de deslocamento de pessoas e bens na área urbana, "[..]"

muito além de ser uma questão apenas das condições de deslocamento e de uso de meios de transporte, traduz relações dos indivíduos com o espaço - seu local de vida - com os objetos e meios empregados para que o deslocamento aconteça, e com outros indivíduos. É, portanto, produto de processos históricos que refletem características culturais de uma sociedade.

Logo, se entende como o reflexo da economia que a mobilidade de cada indivíduo que compõe a sociedade urbana, seus diversos deslocamentos, acontece em relação à transformação dos espaços na cidade, refletindo diretamente na estruturação social e ambiental. Levando a importância do transporte, elemento imprescindível para a relação homem x espaço $x$ tempo, resumindo, todas as formas de deslocamento, ocupação e desenvolvimento, seja ela econômica política ou social, são interligadas ao transporte, que quando bem planejado, a infraestrutura e a prestação de serviços não se limitam apenas a ganhos, a escolha de um modelo de transporte adequado permite qualidade dos serviços prestados (custos, conforto, segurança, confiabilidade), a integração com outros transportes, redução dos problemas ambientais (congestionamentos, emissão de poluentes, redução dos acidentes de trânsito), além de promover ações sustentáveis para os espaços urbanos, bem como garantir uma melhoria na qualidade de vida da sociedade, eles operam, também como catalisadores do desenvolvimento de áreas ur- 
banas, do crescimento econômico e da igualdade social.

O VLT é um exemplo de transporte limpo, sustentável, rápido e seguro, de média capacidade de transporte e que pode reutilizar linhas férreas dos antigos comboios de trens. Inclusive ser implantado em corredores exclusivos onde sua velocidade pode chegar a $80 \mathrm{~km} / \mathrm{h}$ ou em calçadões e centros históricos dividindo a via com veículos e pedestres com velocidade de $20 \mathrm{~km} / \mathrm{h}$ ou até menos, é uma grande opção para o transporte urbano. Grande parte de locomoção se dá na superfície terrestre, possui baixo ruído e poucas vibrações, pode ser movido à eletricidade e/ou a diesel sendo um transporte menos poluidor do que os demais (Alouche, 2008, p. 38).

Quadro 1 - Dados Operacionais do VLT Porto Maravilha

\begin{tabular}{|c|c|}
\hline Altura $(\mathrm{m})$ & 3,82 \\
\hline Capacidade de Passageiros (composição) & 400 \\
\hline Composição de Unidade & Módulos Articulados \\
\hline Comprimento do Veículo $(\mathrm{m})$ & 30 \\
\hline Extensão $(\mathrm{km})$ & 28 \\
\hline Funcionalidade & Urbano \\
\hline Largura $(\mathrm{m})$ & 2,65 \\
\hline Movimentação & Bidirecional \\
\hline Velocidade máxima $(\mathrm{km} / \mathrm{h})$ & $70 \mathrm{~km} / \mathrm{h}$ \\
\hline
\end{tabular}

Fonte: (BERNARDES, 2014).

\subsection{Transporte e legislação}

O VLT da cidade do Rio de Janeiro utiliza uma tecnologia inovadora nacional e de menor custo de investimento, o uso da energia embarcada (baterias e/ou supercapacitores), com alimentação em pontos específicos (paradas e cruzamentos principais), sem a utilização de elemento de captação de energia aéreo, ou seja, sem o uso de pantógrafos, como condicionante para os projetos de reurbanização da área central. Além disso, possui o uso do biodiesel como combustível, e cabos e conectores de interface com o veículo para geração de energia.

A análise dos critérios operacionais e funcionais é incontestável, o modelo é 
constituído de quatro passos sequenciais para análise: geração de viagens, distribuição de viagens, escolha modal e alocação das viagens às rotas, dando aos passageiros a vantagem de tentar maximizar a utilidade da sua escolha, ou seja, sua escolha parte dos princípios de custos associados aos seus benefícios, resultando no melhor valor da tarifa e as projeções dos itinerários de passageiros.

De acordo com o Instituto de Pesquisas Econômicas Aplicadas é importante conhecer a história da política do Governo Federal para o Setor de Transportes Urbanos, e destaca que nos anos 1960 as práticas relacionadas aos transportes eram efetuadas de maneira desconectadas, sem uma visão holística do tema (IPEA, 2011).

O transporte urbano, ainda que sem uma visão de sistema, foi considerado importante, pelo Grupo Executivo de Integração da Política de Transportes (GEIPOT) em 1965, formado pelo Ministro da Viação e Obras Públicas, pelo Ministro da Fazenda, pelo Ministro Extraordinário de Planejamento e Coordenação Econômica e pelo Chefe do Estado Maior das Forças Armada.

Entre meados das décadas de 1960 e 1980, quando se observa um esforço mais coeso - embora com algumas incoerências - de construção de uma política nacional de desenvolvimento urbano, com uma ativa participação federal sobre o transporte das cidades brasileiras. Particularmente no setor de transporte urbano, esse período possui como marco inicial a criação de algumas instituições que se tornariam as referências técnicas e financeiras do setor (IPEA, 2011).

A partir da Lei no 6.261, de 14 de novembro de 1975, que tem como objetivo promover e coordenar a Política Nacional de Transportes Urbanos foi criado o Sistema Nacional de Transportes Urbanos (SNTU) e a Empresa Brasileira de Transportes Urbanos (EBTU). O SNTU abrange os sistemas metropolitanos e os sistemas municipais (BRASIL, de 14 de novembro de 1975).

Lembrando que, tanto a Lei no 5.917/73, quanto à Lei 6.261/75, que modificou a primeira que aprovava o Plano Nacional de Viação, já tinham sentido a necessidade de um sistema nacional de transportes unificado, visando uma coordenação racional entre os sistemas federal, estaduais e municipais.

O conselho das Cidades, por força da Resolução no 34, de 01 de julho 2005, res- 
salta a importância do termo mobilidade e mudou o nome de Plano de Transporte Urbano Integrado, definido no Estatuto das Cidades, para Plano Diretor de Transporte e da Mobilidade - PlanMob (MINISTÉRIO DAS CIDADES, 2007). Nota-se que, a legislação relacionada à questão dos transportes, está evoluindo cada vez mais associando a melhoria da qualidade de vida da população.

1.3 Viabilidade econômica e financeira

Os aspectos econômico-financeiros são imprescindíveis na aplicação dos projetos de transporte, a possibilidade de subsídios, período de concessões ou parceiras público privado (PPP) determinam a gestão de transporte público, não só na cidade do Rio de Janeiro, como no Brasil. Mas no caso do VLT no Rio de Janeiro, houve o financiamento e subsídio por parte do Estado.

O VLT do Rio é integrado ao Bilhete Único Carioca que atende a todos os transportes públicos da cidade (metrô, barcas, teleférico, BRTs, rede ônibus convencionais), sem a necessidade de funcionários para o acesso dos passageiros ao sistema, sendo feita a recarga através de máquinas nas plataformas. $O$ valor da tarifa do VLT custa $R \$ 3,80$, podendo ser feita integração com baixo custo.

Seu custo de implantação foi extremamente elevado, em função da sua execução, buscando a valorização urbana moderna e a utilização de uma tecnologia veicular, avaliado em $\mathrm{R} \$ 1,157$ bilhão, sendo $\mathrm{R} \$ 532$ milhões com recursos federais do Programa de Aceleração do Crescimento (PAC) da Mobilidade e R\$ 625 milhões viabilizados por meio de uma Parceria Público-Privada (PPP). Apesar do alto investimento é visível seus resultados significativos ao avanço de sua implementação, a gestão municipal do Rio de Janeiro assegurou a experiência entre parceria público-privada na modalidade de Concessões Administrativas para as fases de obras e operação, contribuindo significativamente para a gestão de transporte público e manutenção do sistema. 
1.4 Desempenho Ambiental

O VLT além de ser um transporte tecnológico, ele também proporciona a reurbanização ambiental e paisagística integrada no sistema da cidade, tornando-a mais habitável. Podendo assim, contribuir na restauração e reorganização da paisagem urbana. O VLT se destaca pela utilização de energia inovadora, usando uma energia limpa, não poluente - tecnologia desenvolvida com terceiro trilho energizado para geração de energia, e nas frenagens há o armazenamento de um equipamento chamado supercapacitor.

\section{JUSTIFICATIVA}

A justificativa para a elaboração deste projeto está ligada basicamente a ideia de apresentar um breve relato do transporte público sobre trilhos, o VLT - Veículo Leve sobre Trilhos. Suas principais características e especificidades quanto à tecnologia utilizada, mobilidade urbana e renovação urbana. A escolha da cidade do Rio de Janeiro como cenário deste trabalho se deu pelo da importância desta cidade no cenário brasileiro.

\section{METODOLOGIA}

\subsection{Renascimento do bonde: VLT}

Os bondes eram utilizados em diversas cidades brasileiras ainda na segunda metade do século 19. Em seguida, com a criação de geradores e distribuidores de energia elétrica, a tecnologia evoluiu e alcançou inúmeras cidades, o que o tornou o meio de transporte coletivo mais acessível e utilizado pela sociedade. O Brasil possuía a maior e mais complexa rede de bondes do mundo. 
Bonde era o meio de transporte público coletivo mais importante do país, mas com a crise mundial as pessoas mudaram para a área rural da cidade, diminuindo a utilização dos bondes e fazendo com que o sistema não realizasse expansões devido desinteresse das empresas operadoras sujeitas ao controle das tarifas exercido pelas administrações locais, por não terem mais passageiros que sustentassem. Com isto, abriu-se espaço para outras formas de mobilidades de transporte público, que passaram a concorrer com os bondes já existentes.

Essas mudanças acarretaram na tentativa de retomar a utilização dos bondes no transporte público coletivo do Rio de Janeiro, os modernizado e inovando tecnologicamente, conhecidos agora como "Veículos Leves sobre Trilhos" (VLT).

Hoje, dentre as dezenas de sistemas de bonde que já existiram na cidade do Rio de Janeiro, apenas o bonde de Santa Teresa é único remanescente dedicado para o transporte de turistas sendo um dos cartões postais da cidade, tombado como patrimônio histórico nacional. No entanto, a única linha existente está paralisada desde 2011 quando ocorreu um sério acidente e passa por processo de reforma e modernização.

\subsection{Bonde X VLT}

A comparação entre os antigos Bondes e o VLT parece improvável, mas é possível. O bonde antigo que restou dos diversos que circulavam pela cidade do Rio, hoje, circula apenas em Santa Teresa, mas antigamente ele também levava e trazia passageiros nas principais ruas. Com o passar do tempo, os trajetos começaram a ficar restritos e com horários e dias específicos de funcionamento. Há de convir que VLT não tem nem de longe o mesmo charme do bondinho, mas ao rodar pelo Rio, ainda que em uma área restrita e modernizado ele parece resgatar um pedaço da história da cidade. Apenas 600 metros separam o bondinho de Santa Teresa do meio de transporte coletivo mais moderno da cidade, o VLT (Veículo Leve Sobre Trilhos). Este que resgata a essência dos bondes utilizados antigamente, usando seu jeito tradicional de se mobilizar por uma parte da cidade, trazendo lembranças. Com os vagões todos envidraçados faz com que os passageiros e turistas tenham uma vista dos prédios históricos, fazendo com que muitas vezes não façam questão de utilizar os bancos, a população abraçou este projeto inova- 
dor.

O Rio de Janeiro é o segundo local do mundo a ter um VLT 100\% livre de cabos aéreos de energia. $\mathrm{O}$ sistema fornece eletricidade pelos trilhos, que são energizados nas estações de paragem. Cada vagão tem um condutor que o acelera a uma velocidade máxima de $50 \mathrm{~km} / \mathrm{h}$. O trecho em funcionamento atualmente tem $15 \mathrm{~km}$ de extensão e 15 estações, no futuro serão $28 \mathrm{~km}$ e 28 paradas.

\section{CONCLUSÃO}

Vimos que há uma dificuldade sobre o assunto que reflete o cenário de transporte público coletivo de média capacidade na cidade do Rio de Janeiro, buscou-se demonstrar a importância do planejamento do transporte e implantação do VLT (Veículo leve sobre Trilhos), que supri uma realidade específica e propõe soluções para atender uma demanda local e solucionar conflitos existentes, sendo rápido e simples, aproveitando e adequando o sistema viário já existente. Mostrando ser um veículo possuidor de atributos que satisfaz necessidade da população brasileira de melhoria no setor de transporte público de passageiros, oferecendo transporte público sustentável de qualidade, com o intuito de diminuir o tempo de trajeto e o custo, minimizando também, o impacto ambiental, que ainda sofre muito com esse mal.

Não são explícitos os valores e tempo de investimentos no Rio de Janeiro. Contudo, percebe-se que se existissem maiores investimentos e interesse neste setor, o amadurecimento intelectual e crítico da sociedade em visão de gestão pública da cidade seria garantido pelo direito de ir e vir, sem qualquer prejuízo econômico e social, facilitando o acesso a todos os espaços, assegurados no respeito ao próximo, construindo uma sociedade mais justa, inclusiva e sustentável.

O VLT movido à eletricidade é uma opção que revolucionou o setor de transporte de passageiros na cidade do Rio de Janeiro, por ser eficiente, com o uso de energia renovável e não poluente, e pela qualidade dos serviços, sendo um bom candidato para o estímulo à maior utilização do transporte público coletivo de maneira rápida e eficiente. 


\section{REFERÊNCIAS}

ABEPRO. Disponível em: <http://www.abepro.org.br/biblioteca/enegep2011_tn_ sto_135_862_18698.pdf>

ANTP Disponível em: <http://files-server.antp.org.br/_5dotSystem/download/ dcmDocument/2015/06/15/1D56A37C-09D3-4ABE-980F-C1330F7EF869.pdf>

ANTP. Disponível em: <http://files-server.antp.org.br/_5dotSystem/download/ dcmDocument/2015/06/15/63D8F4EA-22F5-4E4B-A93C-F6EA371300E4.pdf>

Associação Nacional dos Transportadores de Passageiros sobre Trilhos. Mobilidade Sustentável. Disponível em: <https://anptrilhos.org.br/vlt-mobilidade-sustentavel/>. Rio de Janeiro. Brasil

Caderno Técnico VLT. ANP Trilhos. Disponível em: <https://anptrilhos.org.br/vlt-caderno-tecnico-veiculo-leve-sobre-trilhos/>. Rio de Janeiro.

Diário do Porto: Disponível em: <https://diariodoporto.com.br/vltcarioca-dois-anos-crescimento-publico/> Acesso em 8 de junho de 2019. Rio de Janeiro. Brasil

Dissertações. Disponível em: <http://www.dissertacoes.poli.ufrj.br/dissertacoes/dissertpoli981.pdf>

Estudo Preliminar de Implantação VLT RIO. <https://revistas.fee.tche.br/index.php/ indicadores/article/viewFile/2764/3101 https://repositorio.ufsc.br/bitstream/handle/123456789/121988/Estudo\%20Preliminar\%20de\%20Implanta\%C3\%A7\%C3\%A3o\%20do\%20VLT\%20no\%20Cen\%C3\%A1rio\%20 da\%20Mobilidade\%20Urbana\%20na\%20Regi\%C3\%A30\%20Metropolitana\%20de\%20 
Florian\%C3\%B3polis.pdf?sequence=1>

Revista Economica. Disponível em: <http://www.revistaeconomica.uff.br/index.php/ revistaeconomica/article/viewFile/71/186>

Sempre Rio. Disponível em: <http://semprerio.com.br/tecnologia-do-vlt-carioca/>

Solução Inteligente Para Mobilidade. Disponível em: <https://www.aecweb.com.br/ cont/a/vlt-e-solucao-inteligente-para-mobilidade_16147http://monografias.poli.ufrj. $\mathrm{br} / \mathrm{monografias/monopoli10018736.pdf>}$

Universidade Federal do Rio de Janeiro. Solução Inteligente para Mobilidade. Disponível em: <https://www.autoinforme.com.br/artigo-vlt-e-solucao-inteligente-para-mobilidade/>

VLT RIO: Disponível em: <https://www.vltrio.com.br/\#/noticias/vlt_news_site_172>. Acesso em: 5/junho/2019. 